\title{
Altazor o el viaje en paracaídas: creación transdisciplinaria en espacios alternativos a partir del displazement
}

Altazor o el viaje en paracaídas: Transdisciplinary creation in
alternative spaces from displazement

María Teresa Paulín Ríos

María de Lourdes Pérez Cesari

Mayra Edith Simón Fuentes

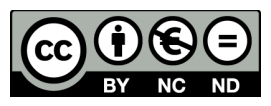

Esta obra está bajo una licencia Creative Commons Reconocimiento-No comercial-Sin Obra Derivada 


\title{
Altazor o el viaje en paracaídas: creación transdisciplinaria en espacios alternativos a partir del displazement
}

\section{Altazor o el viaje en paracaídas: transdisciplinary creation in alternative spaces from displazement}

\author{
María Teresa Paulín Ríos ${ }^{1}$ \\ Universidad Autónoma del Estado de Hidalgo \\ México \\ María de Lourdes Pérez Cesari ${ }^{2}$ \\ Universidad Autónoma del Estado de Hidalgo \\ México \\ Mayra Edith Simón Fuentes ${ }^{3}$ \\ Universidad Autónoma del Estado de Hidalgo \\ México
}

Recibido: 30 de marzo de 2019 Aprobado: 05 de julio de 2019

1 Profesora Investigadora de tiempo completo en el Instituto de Artes de la Universidad Autónoma del Estado de Hidalgo (UAEH). Doctora en Estudios Teatrales por la UAEH. ORCID: 0000-0002-36987623. Correo electrónico: teresapaulin@gmail.com

2 Profesora Investigadora Asociada "B" de tiempo completo en el Instituto de Artes de la UAEH. Maestrante en Apreciación y Creación literaria por la Universidad Veracruzana. ORCID: 0000-00026984-3968. Correo electrónico: maria_perez9640@uaeh.edu.mx

3 Pasante de la Licenciatura en Arte Dramático del Instituto de Artes de la UAEH. Correo electrónico: maiieedf16@gmail.com

ESCENA. Revista de las artes, 2020, Vol. 80, Núm. 1, pp. 54-68 ISSN 2215-4906 
Altazor o el viaje en paracaídas: creación transdisciplinaria en espacios

Artículo

alternativos a partir del displazement

\section{Resumen}

La puesta en escena Altazor o el viaje en paracaídas, dirigido por María Teresa Paulín Ríos a partir del poema de Vicente Huidobro, es un proyecto de investigación transdisciplinaria financiado por el Programa de Mejoramiento del Profesorado (PROMEP). Su objetivo fue la creación de un espacio íntimo a través de un lenguaje nacido del sincretismo entre el displazement, la disciplina del desplazamiento, y el teatro. Para adquirir la técnica del primero se requiere de un alto grado de compromiso físico y emocional y al igual que la actuación, se basa en la inteligencia creadora del practicante. Tras semanas de intenso trabajo, los actores lograron sustraer el peso de sus cuerpos a través del control del movimiento, convirtiendo el espacio en un universo dónde actores y espectadores pudieron compartir su mundo interior.

Palabras clave: transdisciplinario; displazement; teatro; Altazor; actuación

\section{Abstract}

The staging of Altazor o el viaje en paracaídas, directed by María Teresa Paulín Ríos, based on Vicente Hudobro's poem, is a transdisciplinary research project funded by the Programa de Mejoramiento al Profesorado (PROMEP). Its objective was the creation of an intimate space through a language born of the syncretism between Displazement (the discipline of displacement) and theater, considering that to acquire the technique of this discipline requires a high degree of physical and emotional commitment which, like acting, is based on the creative intelligence of the practitioner. After week of practice, the actors managed to subtract the weight of their bodies through movement control, turning the space into a universe where actors and spectator could share their inner worlds.

Keywords: transdisciplinary; displazement; theater; Altazor; performance

ESCENA. Revista de las artes, 2020, Vol. 80, Núm. 1 (julio-diciembre), pp. 54-68 


\section{Introducción}

La puesta en escena Altazor o el viaje en paracaídas, texto de Vicente Huidobro, adaptado por la Dra. María Teresa Paulín Ríos, se presentó del 25 de febrero al 2 de marzo del 2019 en las instalaciones del Instituto de Artes de la Universidad Autónoma del Estado de Hidalgo (UAEH), en México. El trabajo fue resultado del "Proyecto de creación transdisciplinaria ${ }^{4}$ en espacios alternativos a partir del displazement ${ }^{5}$ ", financiado por el Programa de Mejoramiento del Profesorado (PROMEP), emisión 2018-2019. María Teresa Paulín Ríos y María de Lourdes Pérez Cesarí, autoras de este artículo e investigadoras del Instituto de Artes en el área de Teatro, reflexionan en este texto sobre la pregunta inicial que dio origen al proyecto: ¿es posible crear un espacio de intimidad, en un lugar al aire libre, a través de un nuevo lenguaje que nace del sincretismo entre el displazement y el teatro?

El estudio del displazement, como herramienta para la escena contemporánea, es iniciativa de Armand Álvarez y nace del interés por generar un sincretismo entre el esta disciplina del desplazamiento y el teatro. Su búsqueda comenzó en 2009 y en 2011 se creó el proyecto "MigrArte, del cemento a la carpa", financiado por el Programa de Apoyo a la Docencia, Investigación y Difusión de las Artes (PADID). Posteriormente, en 2014, nació el "Taller laboratorio parkour como recurso escénico" en el Centro Nacional de las Artes (CENART), gracias nuevamente al PADID; mismo que dio pasó a la creación del proyecto "Taller-laboratorio displazement como recurso escénico", apoyado por el Fondo Nacional para la Cultura y las Artes (FONCA) en 2015. Este último concluyó con la presentación del prefacio de la obra Altazor o el viaje en paracaídas de Vicente Huidobro, un ejercicio escénico presentado en el patio central del Centro de las Artes de Hidalgo.

Displazement es un término creado por Armand Álvarez, María Teresa Paulín y Soxacen Rodríguez en 2015. Se trata de una variable del parkour, deporte que inició como disciplina en los años ochenta, por un grupo de jóvenes de estrato de clase media baja, mismos que se nombraron Yamakasi. Fue concebido en las ciudades de Lisses, Evry y Sarcelles, en los

${ }^{4}$ La creación transdisciplinaria consistió en la trascendencia de la técnica del displazement y de las herramientas actorales, a favor de un lenguaje sustentado en el movimiento, el cual además no utiliza el texto como base de la puesta en escena.

${ }^{5}$ La disciplina del desplazamiento, originada a partir del Parkour.

6 María de Lourdes Pérez Cesari realizó un exhaustivo seguimiento del proceso de puesta en escena y de las presentaciones de la misma, con la finalidad de generar un registro consistente del trabajo realizado por la compañía Naranja-Escena.

7 El Estado de Hidalgo se encuentra en la región central de la República Mexicana.

ESCENA. Revista de las artes, 2020, Vol. 80, Núm. 1 (julio-diciembre), pp.54-68 
Altazor o el viaje en paracaídas: creación transdisciplinaria en espacios

Artículo alternativos a partir del displazement

alrededores de París; como respuesta a la necesidad de desarrollar habilidades psicomotrices los jóvenes utilizaron como medio principal las estructuras urbanas propias del entorno. Aproximadamente treinta años más tarde, diferentes marcas de bebidas energéticas e instituciones buscaron beneficiarse a través de las competencias. Actualmente, la Federación Internacional de Gimnasia (FIG) terminó por apropiarse del parkour, cambió su sentido original y la definió como un sistema competitivo, orientado a practicarse en espacios cerrados.

Por su parte, el displazement comparte tanto las herramientas como la técnica del parkour, no obstante existe una diferencia sustancial entre estas actividades: su filosofía, pues el deporte difiere del carácter equitativo y cooperativo que promueve la nueva disciplina. El displazement es una alternativa de educación física, mental y espiritual, misma que aporta un sistema educativo sustentado en el movimiento; promueve y desarrolla valores pilares como el respeto, la voluntad, la valentía y la creatividad, además de estar orientado al crecimiento personal a través del movimiento.

El displazement, por lo tanto, requiere de un alto grado de compromiso físico y emocional, vital en el proceso de adquisición de la técnica. Además, busca a través de la inteligencia creadora ${ }^{8}$, gestar un conocimiento corporal profundo, así como el desarrollo de la capacidad de adaptación en espacios alternativos, generalmente al aire libre. Esta disciplina rompe con la convención social del movimiento en las estructuras públicas; de tal suerte que el practicante terminará usando una banca, no para sentarse sino para saltar.

\section{Antecedentes}

Antes de abordar el sincretismo propuesto en la investigación, existió un interés previo: la curiosidad por comprender y poner en práctica la "levedad", un concepto utilizado por Ítalo Calvino en su libro Seis propuestas para el próximo milenio, planteado como un valor que nos permite reconstituir la literatura actual, a través de una nueva perspectiva del mundo. La levedad puede ser explorada dentro de otros campos artísticos, a partir de la transdisciplina:

En los momentos en que el reino de lo humano me parece condenado a la pesadez, pienso que debería volar como Perseo a otro espacio. No hablo de fugas al sueño o a lo irracional. Quiero decir que he de cambiar mi enfoque, he de mirar el mundo con otra óptica, otra lógica, otros métodos de conocimiento y verificación. (Calvino, 1998, p. 16)

8 Concepto de José Marina (1993) para referirse a la inteligencia que incide en el descubrimiento de posibilidades personales, al seleccionar metas y ejecutarlas de forma independiente por medio de la capacidad imaginativa y lúdica encaminada a la acción.

ESCENA. Revista de las artes, 2020, Vol. 80, Núm. 1 (julio-diciembre), pp. 54-68 
La metodología en esta investigación consistió en el uso del displazement como un método de conocimiento y verificación, una técnica concreta que se vale del movimiento para catapultar al actor a un universo distinto del universo ordinario. Apoyados en la técnica de displazement, los actores sustrajeron el peso de la vida cotidiana, aniquilando tanto su pesadez, como la de los espectadores que participaban en el espectáculo a través de una imaginación activa. El sincretismo nace del uso de las herramientas de esta disciplina, mismas que, aunadas a las actorales y a la filosofía del displazement, crean un lenguaje sustentado en el desplazamiento.

La levedad también resulta una inquietud para el filósofo francés Gastón Bachelard, quien la visualiza como una propuesta que nos permite alejarnos de lo racional y comprender las imágenes desde nuestro universo sensible:

Se trata de arrojar lejos de nosotros todos nuestros pesos, todos nuestros pesares ... se trata de arrojar al mar todo nuestro ser pensante, a fin de que desaparezca para siempre. Así aniquilaremos nuestra doble pesadez, lo que es en nosotros tierra, lo que en nosotros es pasado íntimo oculto. Entonces resplandecerá nuestro doble aéreo. (Bachelard, 2012, p. 179)

Inspirados en la levedad, el grupo de trabajo debió practicar durante semanas para lograr sustraer el peso del cuerpo, no solo de manera metafórica. Concentrados en el control del movimiento, los actores dedicaron largas horas al dominio de la técnica hasta que resultó imperceptible.

Imagen 1. Armand Álvarez, integrante del montaje, ejecutando un frontflip

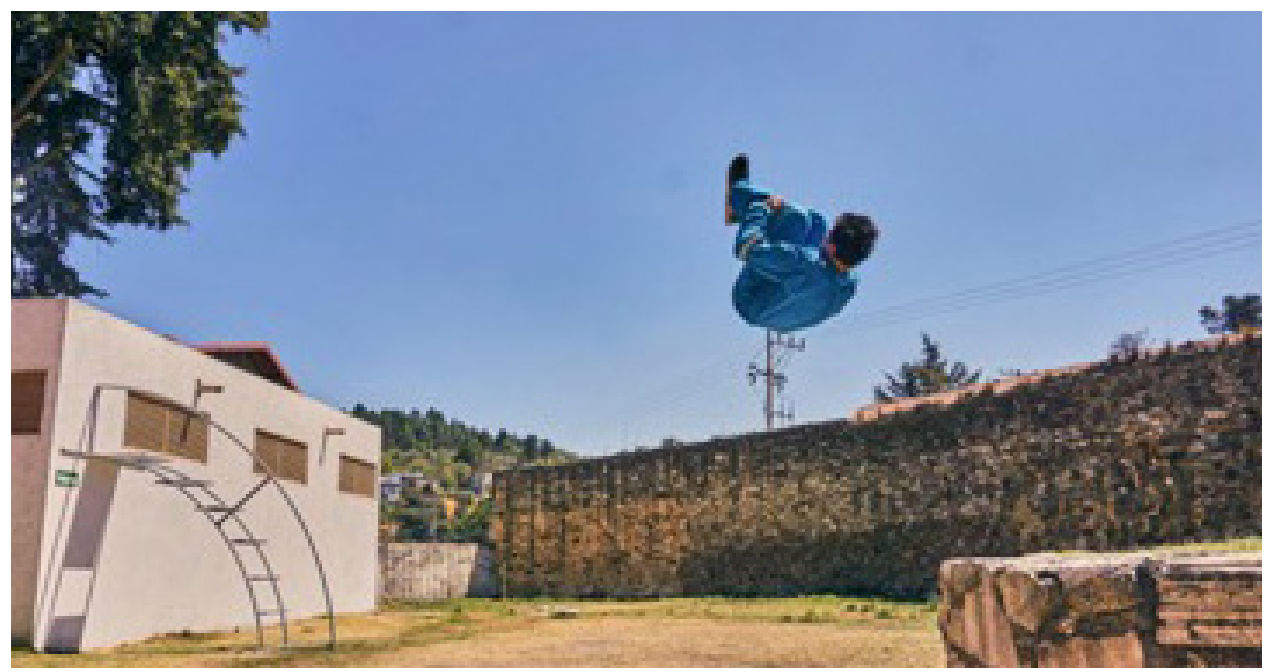

Fuente: Armand Álvarez, 2019. Registro fotográfico de la obra. 
Altazor o el viaje en paracaídas: creación transdisciplinaria en espacios

Artículo alternativos a partir del displazement

Cabe mencionar que el movimiento por sí mismo no era suficiente para la creación de un sincretismo. Es decir, poner actores a saltar habría sido una solución inmediata, un lugar común. El poema Altazor o el viaje en paracaídas, de Vicente Huidobro, se convirtió en un elemento perfecto para potenciar el trabajo interior de los actores y con ello transformar un espacio público, para alcanzar los objetivos deseados.

El texto asocia de manera directa una serie de imágenes entre el viaje y la altura. Al ser un poema, esta obra literaria no corresponde a las exigencias tradicionales de un texto dramático, pues en realidad resulta un escrito complejo, tanto por su multiplicidad semántica, como por los juegos de sintaxis, las largas secuencias de enumeraciones, los juegos irracionales y la falta de una narrativa lineal. El texto tampoco tiene un sentido mimético, pues no refleja la realidad de una manera verosímil'?.

\section{El montaje de la puesta en escena}

El proceso de montaje de la puesta en escena tuvo una duración aproximada de mes y medio de trabajo, en el cual participaron cinco actores ${ }^{10}$ y una escritora de escenario ${ }^{11}$. Es importante destacar que, durante años, los actores integrantes de la compañía Naranja-Escena habían practicado la disciplina del desplazamiento, con lo que desarrollaron un alto grado de control y consciencia corporal, capital para el espectáculo; una de las razones por las que fueron seleccionados.

En una primera etapa del trabajo, fue necesario realizar un análisis de las instalaciones dentro del Instituto de Artes de la UAEH. El punto de partida fue la búsqueda de un espacio alternativo para la realización del montaje. Se optó por el uso de las áreas verdes, debido a la amplitud espacial, la posible integración de los elementos arquitectónicos y de las estructuras artificiales ${ }^{12}$. Este plano descubierto, expuesto al aire libre, mantenía una arquitectura inherente a su contexto y evitaba una delimitación rígida que rompiera con la construcción de un espacio liminal entre lo público y lo privado.

9 Desde el punto de vista aristotélico la verosimilitud corresponde a una lógica narrativa tradicional.

${ }^{10}$ Alejandra Luna Rojas, Emmanuel Macías Rangel, Raquel Muñoz Cabo, Joshua González Canales y Armand Esteban Álvarez Elías, este último también fungió como asesor corporal.

${ }^{11}$ María Teresa Paulín Ríos.

12 Llamaremos estructuras artificiales a los elementos impuestos sobre la naturaleza del espacio arquitectónico.

ESCENA. Revista de las artes, 2020, Vol. 80, Núm. 1 (julio-diciembre), pp. 54-68 
Imagen 2. Estructuras artificiales sobre el espacio arquitectónico

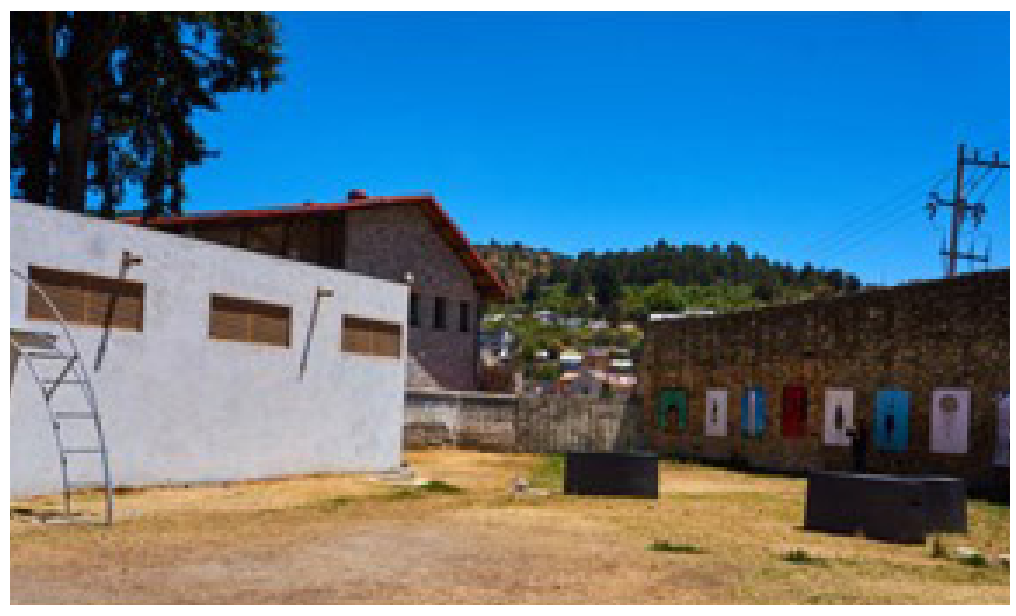

Fuente: Armand Álvarez, 2019. Registro fotográfico de la obra.

Una vez seleccionado el lugar, el diálogo con el espacio a través del movimiento resultó fundamental. Por medio de diferentes dinámicas, en las que se incluyó una práctica rigurosa de la disciplina en las estructuras metálicas, en la construcción de cemento y en las jardineras de piedra, los actores realizaron distintas exploraciones para comprender las exigencias del espacio y sus posibilidades físicas. Cada material se comportaba de manera distinta y tenía solicitudes muy concretas. La estructura tubular que ocupaba el espacio central resultó particularmente reveladora, ya que en un principio los actores realizaron movimientos inmediatos, que respondían a lugares comunes, no obstante, la estructura los rechazó de manera inminente. Con el paso de las exploraciones se descubrió el ritmo y la calidad del movimiento con la cual esta podía ser habitada.

El primer contacto con las estructuras fue para la revisión de las posibilidades físicas. Imaginaba algunos movimientos y trataba de construirlos. Sin embargo, el temor por la extrañeza de la forma de las estructuras hizo que mi prioridad fuese el desarrollo de la habilidad física para poner en práctica mis propuestas. (Macías, entrevista personal, 21 de marzo de 2019)

Dentro de las consignas existía la necesidad de no caer en la ilustración del texto a través del movimiento, pues de resultar así el trabajo no aportaría nada a la puesta en escena. Por lo que se construyeron y utilizaron partituras de movimiento, improvisaciones y juegos infantiles, entre otras dinámicas, mismas que exigían una gran capacidad tanto física como imaginativa de los actores. A partir de estas dinámicas el grupo generaba sus propuestas, para luego mezclarlas, cortarlas, intercambiarlas o transformarlas. Una vez definidos los movimientos y las imágenes que se articularían, los actores fueron apoyados por el asesor corporal, quién después de observar la exploración, logró depurar y filtrar cuestiones técnicas de arraigo, suspensión, equilibrio, estabilidad en superficies, concentración, entre otros ${ }^{13}$.

\footnotetext{
${ }^{13}$ Cabe señalar que estas modificaciones preceden al accidente, en otras palabras, el asesor corporal
} deberá tener una capacidad de observación desarrollada en pro de la anticipación de fatalidades.

ESCENA. Revista de las artes, 2020, Vol. 80, Núm. 1 (julio-diciembre), pp.54-68 
Altazor o el viaje en paracaídas: creación transdisciplinaria en espacios

Artículo alternativos a partir del displazement

Imagen 3. El asesor corporal mostrando la dinámica de movimiento

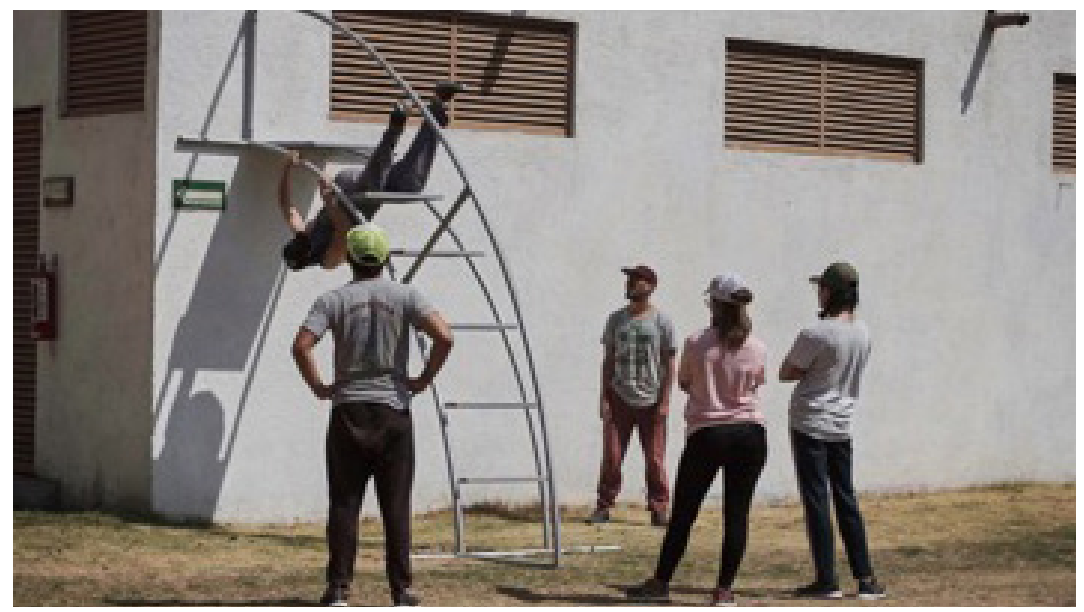

Fuente: Armand Álvarez, 2019. Registro fotográfico de la obra. papel del asesor corporal fue fundamental en la creación de la puesta en escena; una base puntual que proporcionó consistencia a su realización, tanto por sus notas técnicas, como por su asesoría para la construcción de movimientos e imágenes concretas.

Finalmente, el rechazo o la aceptación de las propuestas de movimiento dependió de una concepción concreta de la dirección es-

cénica en torno a la composición, a la experiencia estética o a la definición de secuencias de imágenes. Se sumó al desarrollo del trabajo un segundo proceso de filtración que implicó tanto la reconstrucción de la propuesta para delimitar el margen de error como la modificación minuciosa de la misma. Esto previno riesgos físicos o cuestiones estéticas ${ }^{14}$ relacionadas con el lenguaje que se construyó.

Imagen 4. Observación de los actores durante el ensayo

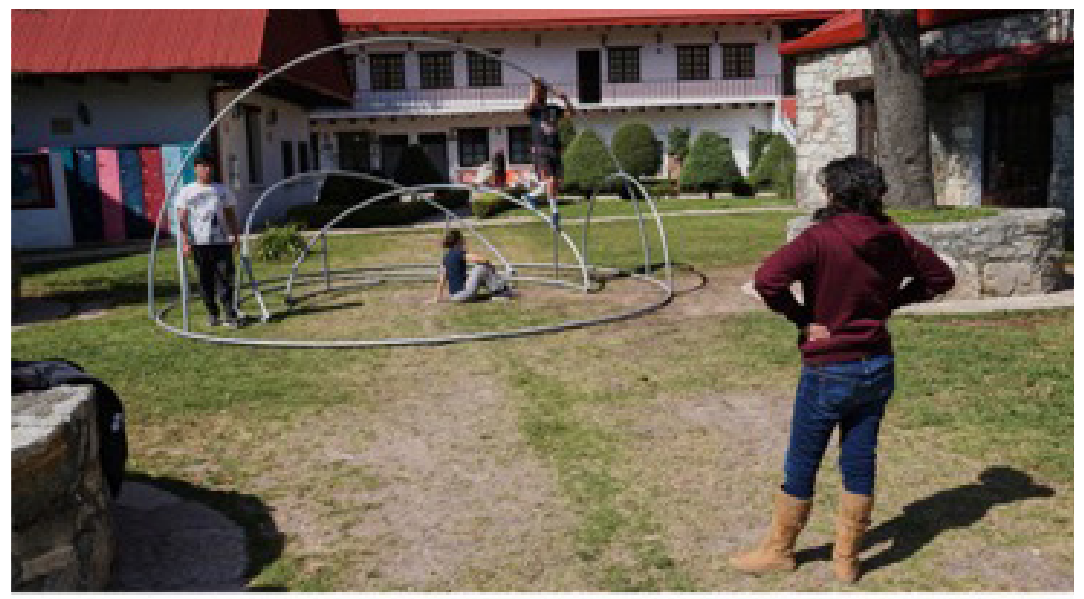

Fuente: Armand Álvarez, 2019. Registro fotográfico de la obra.
Una vez seleccionadas las propuestas de movimiento, el actor tuvo que reconstruirlas con la intención de precisar su ejecución, para generar la confianza necesaria antes de incorporar la palabra; para luego evocar imágenes profundas que le permitieran generar el estado de intimidad indispensable para que el espectador consiguiera reconectarse consigo mismo y liberar su universo interior.

\footnotetext{
${ }^{14}$ Es decir, romper con la simetría, evitar la ilustración del movimiento con la palabra y la aglomeración de elementos en el espacio.
} 
El trabajo se fue mostrando por capas. La primera capa después de la creación de partituras fue la de la memoria, reconocer la estructura y "repetir"; la siguiente implicó la búsqueda de imágenes resonantes, de coherencia y caminos o trampas estructurales en el texto que facilitaran su asimilación. Al final del proceso, en vísperas del cierre, los significados más profundos y resonantes dialogaban para ocupar un lugar en mi lógica de imágenes. En esta etapa hubo un gran descubrimiento personal, ya que las imágenes se veían constantemente confrontadas por nuevas imágenes, que a su vez generaban otras relaciones entre ellas. (Macías, entrevista personal, 21 de marzo de 2019)

Imagen 5. Los actores ensayan sobre la estructura de metal

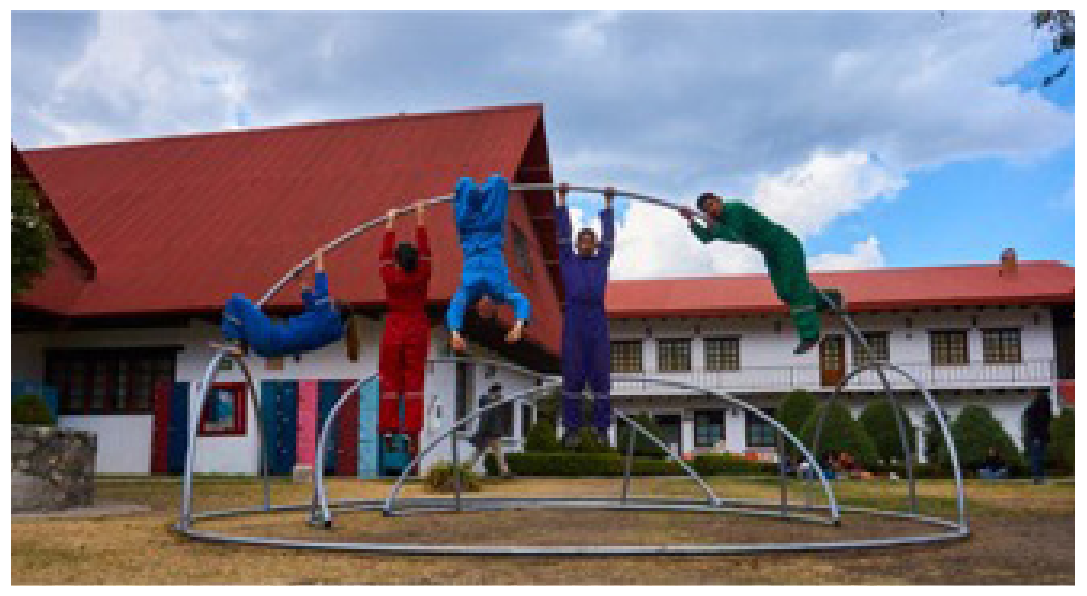

Fuente: Fotografía de Armand Álvarez, 2019. Registro fotográfico de la obra.

No obstante, la construcción de secuencias fue solo uno de los mecanismos de creación, lo cual reiteró que la complejidad de la articulación de esta puesta en escena radicó en su carácter mutable y reformable, que no respondió a un régimen categórico, orden jerárquico o repetición mecánica. Esto último debido a que el riguroso trabajo del actor consistió, como hemos mencionado anteriormente, en reconstruir y no en repetir las secuencias o los movimientos. La articulación se realizó a través de distintos procedimientos, los cuales respondieron a la búsqueda y exploración sobre objetivos concretos. Dicho de otro modo, lejos de reproducir un procedimiento estipulado, la articulación partió de diferentes ángulos y perspectivas; no hubo una construcción lineal, ya que las actividades desarrolladas para la creación de imágenes fueron múltiples y partieron de distintos estímulos.

\section{Las presentaciones}

Al iniciar las funciones se realizaba un protocolo de bienvenida donde se explicaba brevemente al espectador las características del proyecto y ciertas indicaciones para evitar contratiempos en el desarrollo de la puesta en escena. Entre ellas, quizá la más importante, consistía en situar al espectador en el plano central del espacio como punto inicial, invitándole a desplazarse a voluntad durante el desarrollo del espectáculo. Cabe destacar que una 
Altazor o el viaje en paracaídas: creación transdisciplinaria en espacios

Artículo alternativos a partir del displazement

de las características principales de Altazor o el viaje en paracaídas radicó en el uso integral del espacio, que explotaba al máximo sus posibilidades, haciendo que el desplazamiento se convirtiera en uno de los elementos primordiales en la experiencia escénica del público.

Imagen 6. Espacio escénico dividido en cuatro áreas

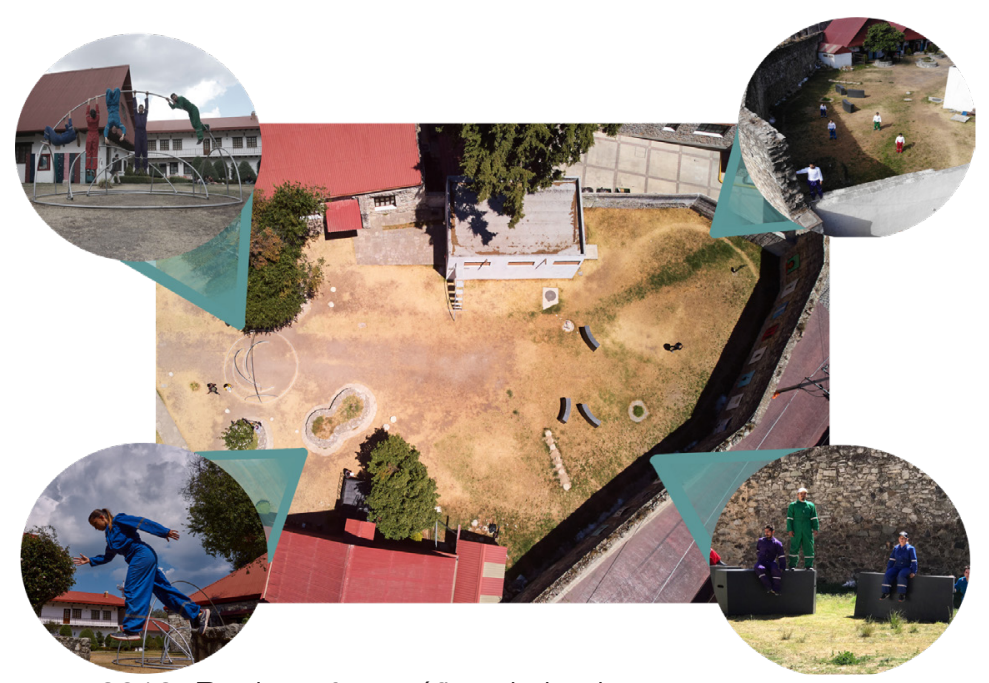

Fuente: Armand Álvarez, 2019. Registro fotográfico de la obra.

Imagen 7. Los actores edificio construyen la imagen del prefacio

Al principio de la puesta

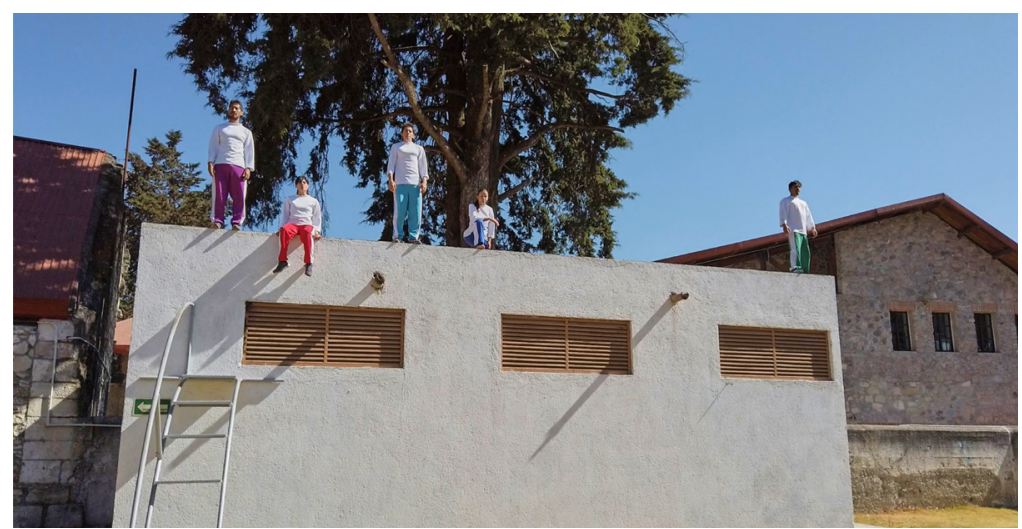

en escena los espectadores se colocaban en el plano central del espacio, frente a la estructura tubular (esquina superior izquierda, imagen 6). Posteriormente, el público continuaba su recorrido con la intención de observar a los actores que trabajaban en el techo del edificio blanco, una construcción de aproximadamente cinco metros de altura, a la que estos últimos accedían por medio de una escalera de metal concebida Fuente: Armand Álvarez, 2019. Registro fotográfico de la obra. para la puesta en escena. En este lugar los actores provocaban a los espectadores con un texto que impulsa al salto: 
Abre la puerta de tu alma y sal a respirar al lado afuera. Puedes abrir con un suspiro la puerta que haya cerrado el huracán.

Hombre, he ahí tu paracaídas maravilloso como el vértigo.

Poeta, he ahí tu paracaídas, maravilloso como el imán del abismo.

Mago, he ahí tu paracaídas que en una palabra tuya puede convertir en un parasubidas maravilloso como el relámpago que quisiera cegar al Creador.

¿Qué esperas?

Mas he ahí el secreto del Tenebroso que olvidó sonreír.

Y el paracaídas aguarda amarrado a la puerta como el caballo de la fuga interminable. (Huidobro, 2009, p. 30)

Al finalizar este texto del prefacio, los actores descendían por las escaleras mientras se colocaban unos overoles de colores, inspirados en la vestimenta de trabajo de los obreros. El vestuario, junto con el Canto I, denunciaba las prácticas capitalistas que reducen al ser humano a convertirse en un hombre hormiga; es decir, en un productor y un consumidor imparable. Habitante de un tiempo vertiginoso y carente de un lugar para el descanso, el hombre hormiga avanzaba hacia su autodestrucción:

Hablo porque soy protesta insulto y mueca de dolor

Solo creo en los climas de la pasión

Solo deben hablar los que tienen el corazón clarividente

La lengua a alta frecuencia

Buzos de la verdad y la mentira

Cansados de pasear sus linternas en los laberintos de la nada

En la cueva de alternos sentimientos

El dolor es lo único eterno

Y nadie podrá reír ante el vacío

¿Qué me importa la burla del hombre-hormiga

Ni la del habitante de otros astros más grandes?

Y yo no sé de ellos ni ellos saben de mí 
Altazor o el viaje en paracaídas: creación transdisciplinaria en espacios

Artículo alternativos a partir del displazement

Yo sé de mi vergüenza de la vida de mi asco celular

De la mentira abyecta de todo cuanto edifican los hombres

Los pedestales de aire de sus leyes ideales

Dadme dadme pronto un llano de silencio

Un llano despoblado como los ojos de los muertos. (2009, pp. 46-47)

Al termino del Canto I, llegaba un momento de silencio, la oportunidad de respirar y beber agua. Los actores volvían a la estructura tubular y comenzaban el Canto II, la llamada a la salvación y a la esperanza, el tiempo se detenía:

Así, en todo poema verdadero se pueden encontrar los elementos de un tiempo detenido, de un tiempo que no sigue el compás, de un tiempo al que llamaremos vertical para distinguirlo de un tiempo común que corre horizontalmente con el agua del río y con el viento que pasa. ... El fin es la verticalidad, la profundidad o la altura; es el instante estabilizado en que, ordenándose, las simultaneidades demuestran que el instante poético tiene perspectiva metafísica.

El instante poético es entonces necesariamente complejo: conmueve, prueba -invita, consuela-, es sorprendente y familiar. En esencia, el instante poético es una relación armónica de dos opuestos. (Bachelard, 2018, p. 94)

A partir del movimiento

Imagen 8. Fragmento del Canto I, función del 2 de marzo 2019

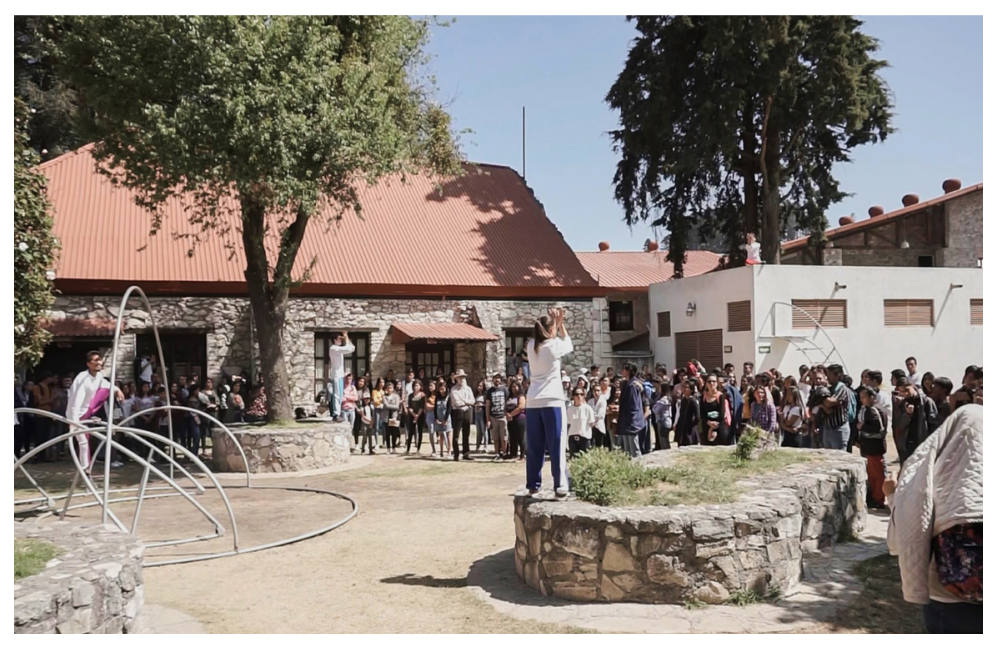

Fuente: Armand Álvarez, 2019. Registro fotográfico de la obra. nuo en el que tanto actores como espectadores se distribuían por todos los planos del espacio, se abría una nueva dimensión en el tiempo. Es decir, la puesta en escena de Altazor o el viaje en paracaídas estaba plagada de instantes poéticos. "El tiempo del instante brotaba" (2018, p. 96) y el espacio se convertía, a través de las imágenes, en el universo dónde actores y espectadores podían compartir su mundo interior: "Aquí se trataba de una participación más íntima en el momiento de la ima- 
gen. Por ejemplo, tendremos que probar, siguiendo ciertos poemas, que la impresión de inmensidad está en nosotros, que no está ligada necesariamente a un objeto (Bachelard, 2010, p. 31).

Actores y espectadores compartían el vuelo, el estado de ensoñación durante la puesta en escena. Al llegar al final del Canto II, uno de los actores de pie sobre una de las bardas del Instituto de Artes, miraba hacia el horizonte; frente a él, se descubría el pueblo, el bosque y las montañas. En esta parte del espectáculo, tanto actores como espectadores daban un nuevo salto hacia el vuelo infinito: "Y al fondo de ti misma recuerdas que eras tú, El pájaro de antaño en la clave del poeta" (2009, p. 55), resonaba el texto de Huidobro. La poesía, la imaginación dinámica, el salto y la caída se manifestaban a través de esta imagen sublime. Actores y espectadores se encontraban expuestos, se reconocían y compartían el instante.

\section{Conclusiones}

La transformación del espacio se llevó a cabo a través de un acto de voluntad, tanto del grupo de trabajo como de los espectadores: de los primeros porque debieron transgredirse para lograr trasladarse entre los distintos universos, desplazarse más allá de la inmediatez y el lugar común en busca de imágenes y emociones profundas, capaces de transportar al público; de los segundos, porque el acto de liberarse implicó correr un riesgo. Es por esta razón que el espectador terminó por construir su propio espectáculo, mediante una participación sensible, que implicó disponerse ante una imagen poética que podía resonar en la profundidad de su ser.

A partir de una técnica como el displazement es posible enriquecer la escena actual, pues esta se fundamenta en el movimiento y en una filosofía de desarrollo cooperativo que involucra el respeto, la voluntad, la valentía y la creatividad. El proceso del practicante de displazement es el mismo que construye el actor durante el acto creativo. El teatro solicita un trabajo grupal y un profundo desarrollo de la consciencia y la corporalidad, pero, sobre todo, de la presencia comprometida de ambos, en un acto que implica riesgo y, por lo tanto, conflicto.

El lenguaje generado en Altazor o el viaje en paracaídas, partió tanto del movimiento interior del actor como del exterior; en conjunto estos contribuyeron a la creación de una experiencia estética íntima que transcendió el movimiento per se, a pesar de suceder al aire libre. El cuerpo del actor, expuesto, suspendido por momentos, colgado en otros, construyó metáforas, imágenes que guiaron la mirada del espectador hacia sus propios misterios personales.

ESCENA. Revista de las artes, 2020, Vol. 80, Núm. 1 (julio-diciembre), pp.54-68 
Altazor o el viaje en paracaídas: creación transdisciplinaria en espacios

Durante el espacio de diálogo generado al final de cada función ${ }^{15}$, uno de los asistentes manifestó: "el espacio se vuelve maleable, como una burbuja que nos contiene; un trabajo energético como un imán entre el actor-espectador" (Borbolla, entrevista realizada por Armand Álvarez, 2 de marzo de 2019). Ello confirma que, a pesar de ser un espacio abierto, el lugar se transformaba en un espacio íntimo capaz de acoger al espectador.

El montaje Altazor o el viaje en paracaídas creó un sitio de encuentro necesario en una época donde la inmediatez, la premura y el acto exprés son ejes rectores de la filosofía que rige el comportamiento contemporáneo. La experiencia brindó al espectador la posibilidad de sustraerse del peso del vivir. A través de un acto de intimidad tanto sensible como profundo, el público tuvo la oportunidad, al menos durante unos momentos, de modificar las dimensiones de su ser.

\section{Referencias}

Calvino, I. (1998). Seis propuestas para el próximo milenio (A. B. Palma, Trad.) Madrid, España: Siruela.

Bachelard, G. (2018). La intuición del instante (4. a ed., J. Ferreiro, Trad.) México: Fondo de Cultura Económica.

Bachelard, G. (2010). La poética del espacio. (E. d. Champourcin, Trad.). México: Fondo de Cultura Económica.

Bachelard, G. (2012). El aire y los sueños (10. ${ }^{2}$ ed., E. d. Champourcin, Trad.). México: Fondo de Cultura Económica .

Huidobro, V. (2009). Altazor y Temblor de Cielo. México: CONACULTA.

Marina, J. A. (1993) Teoría de la inteligencia creadora. Barcelona: Editorial Anagrama.

${ }^{15}$ El documental El espacio íntimo de Armand Álvarez, recoge el proceso de trabajo y gran parte de la puesta en escena. Puede consultarse en el siguiente enlace: https://www.youtube.com/wat$c h ? v=D 1 T V A p E d k \_E$ 